\title{
New technology adoption in US telecommunications: The role of competitive pressures and firm-level inducements *
}

\author{
Sumit K. Majumdar ${ }^{a}$ and S. Venkataraman ${ }^{b}$ \\ ${ }^{a}$ School of Business Administration, Uninersity of Michigan, Ann Arbor, MI 48109, USA \\ b The Wharton School, University of Pennsylvania, Philadelphia, PA 19104, USA
}

Final version received June 1992

In this study we examine the reasons for the differential adoption levels of a new technology, that of electronic switching, across firms in the US telecommunications industry. Using theoretical postulates from the market-structure inducements approach to firm behavior, and the behavioral theory of the firm, we propose that the incentives to adopt a new technology are positively related to the competitive pressures faced by a firm in its micro-market, negatively related to past levels of performance, and positively related to slack availability. Our sample consists of 40 of the largest firms in the industry. We use firm-level data collected for the years 1973, 1978, 1981, 1984, and 1987, and the results indicate strong support for our proposition. Our findings show that, in general, market effects via the mechanism of competitive pressures generated are strong in explaining inter-firm variations in levels of technology adoption in the period since moves to deregulate the industry began; however, the firm-level effects are equally strong, if not stronger, in explaining such variations both in the period leading up to the commencement of deregulatory moves and also immediately thereafter.

Correspondence to: S.K. Majumdar, School of Business Administration, University of Michigan, Ann Arbor, MI 48109, USA.

* We thank Ned Bowman, Neil Gandal, Ian MacMillan, Larry Rhine and session participants at the Academy of Management annual meeting, Miami, FL, 1991, for comments on an earlier draft of this paper. S. Venkataraman has benefitted from a grant from the Sol C. Snider Entrepreneurial Center of the Wharton School, University of Pcnnsylvania.

Research Policy 22 (1993) 521-536

North-Holland

\section{Introduction}

It is by now well accepted, and also well articulated, interalia by Clark [10], Penrose [48] and Solow [63], that investing in relevant new technology is crucial to both a nation's and a firm's ability to remain competitive. Yet, when firms in an industry have access to such new technologies, adoption levels across firms have been demonstrated to be not always uniform, for example by Davies [15], Griliches [22], Lane [29], Metcalf [40] and Rogers [56]. This issue of different adoption levels across similar firms within an industry raises two interesting and important questions. First, what are the factors that determine whether a firm will adopt a given new technology at any given point in time, and second, given that a new technology is available at some time, what is the process by which the new technology spreads, or diffuses, across the population in aggregate? In the US telecommunications industry wide variations in the adoption levels of new switching technology have been known to exist, and in this paper we investigate the question of what are some factors that account for these differences among firms.

Since 1960 when a new technology, that of electronic switching, was developed in the telecommunications industry, representing a significant improvement over the prevailing switching technology, firms in the US telecommunications industry have had a choice of replacing their electro-mechanical switching with the new elec- 
tronic technology. Electronic switching greatly enhances a firm's ability to provide a wide array of value-added services to the customer that they could not do so earlier. This technology increases the scope of telecommunications firms by allowing them to offer tailored services, because electronic switching represents a convergence between the computer and communications industries, and it also reduces costs dramatically as Flamm [19] demonstrates. '

Despite the well-known technological superiority of electronic switches, and the relatively low risks of conversion, the adoption level of the new technology across firms, and across time, has not been uniform. For example, our analysis of the adoption behavior of the top 40 telephone operating companies in the US shows that in 1978 their average proportion of electronic to total installed switches was only $18 \%$. This proportion had increased to $55 \%$ by 1987 , with the dramatic increase being explained as occurring due to the forces of entrepreneurship and competition unlcashed by divestiture [11]. Yet, during the same two time-periods the standard deviations of such adoption levels were $14 \%$ and $25 \%$, in 1978 and 1987 , respectively, thus revealing wide variations in adoption levels between firms. Our interest in this paper rests on the determinants of technology adoption in the US telecommunications industry, and in explaining this empirical phenomenon. While the second question we have articulated in the first paragraph, dealing with the process of diffusion of a given technology, is also interesting and moot, we do not deal with the shape of the diffusion curve, per se, for electronic switching in the US telecommunications industry. ${ }^{2}$ Our study is anchored in the 10 year period 1978-1987, when significant technological and regulatory events took place in the US telecommunications industry. This time-window

\footnotetext{
1. For instance, estimates within the Bell Telephone laboratories [62] and the GTE system [55] suggest that the transition from electro-mechanical to electronic switches reduces annual maintenance and operations costs by $6-7 \%$ of the purchase cost of a switch. Thereafter, a changeover from one generation of electronic switches to the next reduces such costs by a further $2 \%$ of the purchase cost.
}

enables us to investigate a critical issue in a key industry during a period of major change, both cross-sectionally and on a comparative basis.

The paper unfolds as follows. Because we have already highlighted that a distinction exists between adoption and diffusion, in the next section we undertake a brief literature survey on the ideas of both adoption and diffusion. Thereafter, we note the gaps in extant literature suggesting the need for alternative frameworks to explain firm-level variations in the adoption of new technology, and subsequently articulate the framework that we develop, which is principally based on behavioral theories of the firm. The third section contains details of our empirical research design. The fourth section presents the results and is followed by a discussion. The fifth section contains our conclusions.

\section{Literature survey and framework development}

\subsection{Literature survey}

A useful way to commence this survey is to examine the distinction between adoption and diffusion. Thirtle and Ruttan [67, p. 78-79] make a distinction between the two by stating that

Adoption studies consider the reasons for adoption at one point in time, or the reasons for time of adoption of different users. In contrast, most diffusion models are dynamic and study the behavior of the diffusion process over time. Thus, relative to adoption, diffusion

${ }^{2}$ Of course, by adding adoption levels of individual firms at each point in time, and aggregating over time we would have the industry diffusion curve. See Davies [15] and Stoneman [66] for elaborations on this point. Therefore, adoption and diffusion are different dimensions with which to analyze the same underlying phenomenon. What distinguishes one from the other is the unit of analysis, the level of aggregation and the time frame over which each dimension is analyzed. However, we reiterate that our concern in the present paper is with the factors that determine the adoption level at any given point in time. 
may be viewed as a dynamic, aggregative process over continuous time. ${ }^{3}$

Diffusion models have been applied at the level of the individual firm or intra-firm diffusion, at the level of the industry or inter-firm diffusion and imitation, and overall diffusion or inter-industry, inter-sectoral and international diffusion. ${ }^{4}$ The speed with which new technologies have spread, or, in other words, diffused over time has been variously modelled using the sigmoid-shaped curve, which, interalia, has included lognormal and quasi-engel specifications [15], Gompertz specifications [16], a logistic specification [22,40], and a logarithmic reciprocal specification [45]. In all these studies the family of $S$-shaped curves provides a useful means of quantifying the principal underlying assumption about the process of diffusion, namely that it resembles an epidemic.

However, Thirtle and Ruttan [67, p. 101] articulate that the diffusion curves, described above, are intended to model the behavior of firms in the aggregate; it is, therefore, inevitable that they cannot explain why some firms adopt new technology or a new innovation earlier than others. ${ }^{5}$ What induces variations among firms in time of adoptions, or what induces some firms to adopt higher levels of a particular new technology than others are the focus of studies of adoption.

Within the body of literature dealing with adoption, two streams may be identified. The first is the game theoretic approach, as developed by Dasgupta [14], Fudenberg and Tirole [20], Quirm-

\footnotetext{
3 Adoption and diffusion studies are also examples of two distinct modes of explaining social science phenomena, as articulated in Thirtle and Ruttan [67]. Adoption studies are an example of variance theory, where the independent variables are simultaneous, necessary and sufficicnt to explain the variance of the dependent variable. Variance theory, therefore, looks for explanations in terms of forces or variables acting on an individual or social unit. Conversely, diffusion studies are examples of process theories where precursors are necessary for outcomes to occur, but are not sufficient since the process is probabilistic and the outcome only follows a particular time sequence of precursors. Therefore, process theory considers sequences of events leading to a state of affairs.

4 See Davies [15], Rogers [56], Stoneman [66] and Thirtle and Ruttan [67] for excellent and detailed surveys of the diffusion studies.

5 Such a problem was also recognized by Mansfield [41,42]. Stoneman [66] criticizes these models for their lack of economic content and lack of general relevance.
}

bach [49], and Reinganum [50,51]; the second stream essentially includes empirical studies on the determinants of adoption as pioneered by Mansfield [41,42].

To answer the question as to what factors determine whether a firm will adopt a new technology at any point in time, game theorists advance the following proposition. They suggest that the interaction of the profitability of the new technology for the user, combined with relentless pressures from rivals to reduce costs, will determine the exact timing of adoption and who will be leaders and followers. ${ }^{6}$ However, under a continuous-game scenario, the timing and extent of adoption is dependent on the expected payoffs for each firm from adopting a given level of technology at each point in time. To the extent that incentives are different among firms, there will be difference in the timing and levels of adoption because the perceptions of expected payoffs will be different. ${ }^{7}$

${ }^{6}$ Nevertheless, the preoccupation of game theorists has been on the timing of adoption of a new technology, that is should the firm adopt now or later. Their models concentrate on the profitahility of the innovation to the user and have considered the exact timing of adoption under conditions of duopoly [50] or oligopoly [49,51]. The main findings are that even when firms have identical and perfect information about a technology, strategic behavior can lead to a Nash equilibrium with different adoption dates, but as the number of firms increase adoption can be delayed. Reinganum [50] shows that the first-mover or adopter reaps all the benefits of the new technology and hence there is a race to be a leader rather than follower. Her models do not, however, allow for the possibility of preemptive behavior on the part of rivals and instead assume that firms must pre-commit themselves to adoption dates. Assuming preemptive behavior, which may arise as a result of the incentives faced by firms, Fudenberg and Tirole [20] demonstrate that adoption timing will be different.

7 The studies cited above assume that the adoption decision is of a "once and for all" rather than a repeated game variety. That is, there are clear winners and losers, this is a function of their order of adoption, and the level of adoption at any point is complete or zero. However, many technologies may not be of this discontinuous variety. Indeed, the technology under question, electronic switching, may be adopted by firms in a phased manner, and winners and losers may not be sharply distinguishable. If a firm alters its strategy slightly its rewards also change slightly. Models which have incorporated these dynamic elements include Dasgupta and Stiglitz. [13], Dasgupta [14], Kamien and Schwartz [27], Loury [38], Mookerjee and Ray [47], and Reinganum [52]. For reviews of these studies see Dasgupta [14], Kamien and Schwartz [28], and Reinganum [53]. 
Empirical studies pioneered by Mansfield $[41,42]$ have explored the differences in the timing of adoption between firms. From a variety of economic and behavioral factors that have been investigated, two seem important, both theoretically and empirically [15]. These are firm size ${ }^{8}$ and profitability of the investment in the new technology. However, the empirical studies of Mansfield and his followers have been criticized for their ad-hoc theorizing $[15,66]$, and to quote Davies

little is known of the reasons why some firms adopt innovations quicker than others ... the one fairly common finding identified ... large firms tend to be quicker, must be viewed with caution .... By dealing only with the behavior of firms in aggregate, it pushes aside many of the more interesting theoretical questions and substitutes a rather mechanistic hypothesis of behavior .... Even in the literature addressed specifically to explaining inter-firm differences, no attempt is made to formulate a fully-worked theory of firm decision-making ... a realistic but empirically manageable approach to the firm-level adoption decision must be provided [15, pp. 34-36].

We use the above noted lacuna in micro-level theorizing as a point of departure to put forth a behavioral framework which will permit an investigation of different adoption levels of new technology in the US telecommunications industry. While game theoretic models assume that payoffs are calculable, many of the subtletics of actual behavior are overlooked; nevertheless, we recognize the central behavioral insight from game theory that competitive forces, by altering incentive structures, exert strong pressures on managers to adopt new innovations. Also, as Stoneman [65] discovered, in the context of adoption decisions firms are more prone to usc satisfying or heuristic rules, rather than sophisticated calculations of profitability. Our articulation of a framework from a behavioral perspective is, therefore, commensurate with the spirit of the comments encapsulated in this and the previous paragraphs.

8 The issue of size is particularly well studied and the most recent study, by Acs and Audretsch [1], casts considerable doubt on the assumption that large firms in an oligopolistic market or in a monopolistic environment are the ones most likely to be aggressive in technology adoption or be innovative.

\subsection{Framework development}

From a behavioral point of view two perspectives on inducements to adopt new technology can be distinguished, with one emphasizing an external and the other an internal dimension. The external perspective suggests that the incentive to adopt is a function of the competitive pressures faced by a firm in its market within the industry. The internal perspective suggests that the inducement to search for and adopt new technologies is stimulated either by a dissatisfaction with the current level of performance of the firm, called problemistic search, or is stimulated by the existence of slack in the firm, called slack search.

\subsubsection{The competitive pressure hypothesis}

The competitive pressure faced by a firm is a strong inducement to adopt relevant new technology, and as Leibenstein [33] has remarked, competition exerts strong pressures on the managers of a firm to search for new alternatives to current production techniques and also to exert greater efforts. Competitors, through their superior efforts or choice of new technologies, may be able to offer lower prices, thus being able to increase their market share. This induces other firms also "to sell at equally lower prices or face the consequences of continually falling sales which in turn create pressures on firms to reduce costs and/or to seek means of doing so" [33, p. 207]. So far this is a standard economic story. But from a behavioral point of view, as Leibenstein further articulates,

the quest for lower costs transmits itself to individuals, at various levels within the firm, whose sense of success requires the firm to stay profitable or at least solvent, and of whom it is believed, or who themselves believe, that they can influence costs. These pressures translate themselves into attempts to ... seek high productivity points which were previously in the constrained choice set or were unknown [33, p. 207].

To the extent that managers feel their revenue streams are open to predation by competitors the pressures may be keenly felt. Indeed, even Schumpeter [60] had argued that monopolists were not exempt from such pressures, and regarded the threat of entry by rival innovations as 
providing the essential spur to a sitting monopolist. ${ }^{9}$

Carrying the competitive argument further, Kamien and Schwartz [26] have suggested that it is the elasticity of the demand curves facing a firm in its specific local market that induces propensity for inventive activity. In those micromarkets where competition is greater, because of the existence of substitutes, demand elasticities faced by a firm can be expected to be higher, and it is the existence of such demand patterns that induces innovative activity or rapid new technology adoption.

The above line of thought implies that within an industry with multiple markets, because of independent geographic markets or differentiated segments, varying competitive pressures in the micro-market will induce varying adoption levels in the industry. Significantly, there is empirical support for the line of reasoning positing relationships between such micro-market structure and the adoption of new technology, notably by Hannan and McDowell [24,25] in the banking industry, by Levin et al. [35] in the optical scanner industry, and by Rosenbaum [57] in the cement industry; therefore, the micro-market structure literature suggests that there is a positive relationship between the specific competitive pressures faced by a firm in its micro-market, and the inducements for it to adopt a new technology.

\subsection{The firm-inducement hypothesis}

The competitive pressure arguments, nevertheless, assume that all firms are alike. Faced with identical competitive pressures, they predict that firms will behave identically, that is, ceteris paribus, adoption levels will be uniform. However, organization theory posits that even when faced with similar environments firms may still

${ }^{9}$ Following Arrow [3] and Schumpeter [60] a vigorous stream of empirical literature has emerged linking market structure to innovation, led by Scherer [58] and Schmookler [59]. While the findings and conclusions of this stream of literature are still debated, for our purposes it appears that competition does exert pressure to innovate. For example, summarizing the findings of this empirical literature, Dasgupta observes that "there is a positive association between the degree of concentration in an industry and innovative activity within it, so long as concentration is not too great" $[14$, p. 524]. behave differently because of inherent, idiosyncratic differences among them. This perspective suggests that inducement to adopt a new technology may vary across firms because there are differences in how they perceive competitive pressures individually.

The behavioral theory of the firm, as articulated by Cyert and March [12], Leibenstein [33], and March and Simon [43], is relevant here. Two of the central tenets of this theory are that time and attention are scarce resources. Because of these constraints, the theory postulates that managers typically do not attend to or evaluate, instantaneously, all of the opportunities and problems facing them. The theory deflects attention from cost-bencfit calculations or optimization as a determinant of choice, to a focus on search behavior. The search for solutions to problems, or exploitation of new opportunities, are thought to be triggered by events that stimulate people's attention thresholds. Two triggers that have proven quite durable within the theory are dissatisfaction with past performance and slack availability, each of which generates internal pressures on managers and employees to do something to change the status quo.

Notwithstanding micro-market pressures, if past performance is poor or below an acceptable satisficing level, problemistic search is triggered and inducements to change the status quo increase. otherwise, inertia and inducements to follow current routines and procedures dominate. Similarly, if the firm contains a pool of unexploited resources, slack search is triggered and again inducements to change the status-quo increase.

The problemistic search hypothesis suggests that when the performance of a firm is inferior relative to other firms in the industry, its attention is peaked and a search for solutions is triggered. Indeed, as Mansfield notes, "firms with decreasing profits might be expected to be more responsive to a new technique, because they might be expected to search more diligently for new alternatives" in an attempt to improve performance [42, p. 124-125]. Stoneman [65] and Davies [15] make similar arguments about the relationship between poor performance and the incentive to search for and adopt new alternatives. Hence, with lower performance there is a greater likelihood of adopting new technology. 
The empirical evidence on the positive relationship between profitability, liquidity and innovative effort or technology adoption is, at best, tenuous according to Kamien and Schwartz [28]. They also point out that the negative relationship between profitability and technological adoption has not received sufficient attention. In behavioral theory, slack, that is the existence of unexploited resources within the firm, is thought to accumulate over time with repeated success. Slack aids the organization in two distinct ways. First, it conserves the pool of unexploited resources to be used in times of unanticipated and uncontrollable exogenous adversity. Second, it allows what Levinthal and March [36, p. 309] call "irresponsible" search. The presence of slack encourages managers to relax organizational controls thereby motivating search activities that cannot be justified in terms of their immediate expected returns for the organization. Rather, search for new and innovative technologies, even risky technologies, is initiated, "because of their attractiveness to some individuals and sub-units, and tolerated because of the organization's current success in achieving targets" [36, p. 309]. This sort of slack search enhances the probability that new technologies will be discovered, evaluated and adopted or exploited. The behavioral theory of the firm, then, presents a good case for a negative relationship between past profitability and current adoption rates.

The slack search hypothesis suggests that if the firm contains a pool of unexploited resources, in the form of excess liquidity or under-utilized assets, say in the form of a network which permits externalities to be exploited for the benefit of the firm and its managerial cadre, or unexploited refinements in technology, this excess slack may also encourage. However, in such a search process the cost-benefit calculus or expected returns for the firm may not be paramount motivators, as Levinthal and March [30] suggest. This sort of a slack search also enhances the probability that new technologies will be adopted or exploited.

In a similar vein Leibenstein [32,34] also offers an intuitively appealing behavioral explanation for why slack induces search on the part of managers. By applying excess slack in the utilization of new technological opportunities that may be of value to the firm, managers can further their own careers. Also, as Davies [15, p. 61] puts it, "some managers might derive 'kudos' from informing their peers of their experiences with a new, technically advanced innovation." This provides a strong motivation to search for and adopt new technologies. In the content of new technology adoption, those technologies valued by the firm, because of learning spillovers and efficiency enhancements, are more likely to be adopted. Such learning spillovers and efficiency enhancements, in turn, are more likely to be engendered in a larger firm setting, where the potential for learning economies and technology conversion economies are higher. The existence of larger networks provides strong incentives for some managers to champion the adoption of these technologies, and thereby further their own careers.

\subsection{Summary: The testable proposition}

The above theoretical arguments may be summarized into a simple testable proposition. We posit that new technology adoption level is an increasing function of competitive pressures facing a firm in its micro-market, a decreasing function of performance, and an increasing function of slack.

However, we also posit that there is a lagged relationship; that is, adoption in the current period is a function of the above independent variables in some previous period. It is axiomatic that firms do not react instantaneously to both external and internal forces. Rather, there is a period of planning, analysis and evaluation of alternatives before major strategic decisions are taken. Hence, the assumption of lagged relationship is grounded in the reality of how firms behave [37].

Finally, the discussion so far has been of a static nature. As the technology under question may be adopted in a phased manner, over a long period of time, the assumptions of stable environment and stable relationship between adoption levels and inducements are unrealistic. Environments do change over time, and therefore the relative pressures exerted by each of the independent variables should wax and wane. Indeed, in the telecommunications industry the market has become more competitive over time because of deregulation. Therefore, we should see a steady increase in the power of competitive pressures to explain differences in adoption levels. Con- 


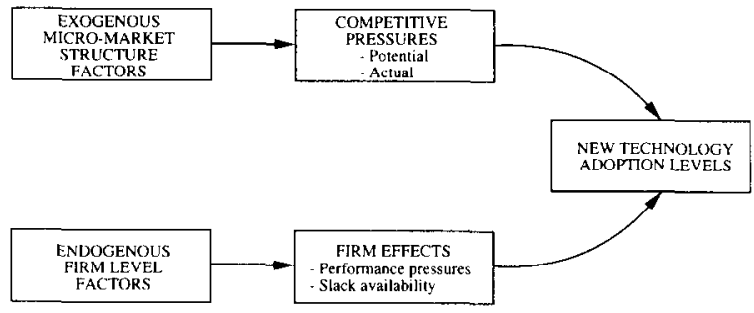

Fig. 1. The inducements of new technology adoption.

versely, in non-competitive periods intra-firm rent-seeking motivations in a semi-monopolistic environment may induce adoption decisions, and these expectations are consistent with the behavioral approaches articulated by Leibenstein [3234]. However, as experience with the use of a technology increases, and as more and more firms adopt the technology, we should see a steady decrease over time in the power of firm-level differences to explain differences in adoption levels.

From a dynamic perspective, we therefore posit that there will be an increase over timc, in the power of competitive pressures to explain differences in adoption levels. Conversely, there will be a steady decrease in the power of firm-level effects over time to explain differences in adoption levels.

Figure 1 shows the inducements to technology adoption argued above.

\section{Research design}

\subsection{Context, sample and data sources}

The research is set in the context of the local operating companies in the US telecommunications industry. There are over 1500 telephone companies in the nation, and approximately 50 of these companies had annual revenues of $\$ 100$ million or more, as reported for the year ending 31 December 1987. These 50 companies accounted for $99 \%$ of all local opcrating company telephone revenues in the nation, amounting to at least $\$ 70$ billion for 1987 . Of these 50 firms, there were at least 21 with annual revenues of more than $\$ 1$ billion or more.

These firms are all the erstwhile Bell operating companies, independents such as Southern New England Telephone, Cincinnati Bell and Roches- ter Telephone Company, telephone operating companies belonging to the GTE group, and the smaller operating groups such as CENTEL, CONTEL and United Telecommunications. The final number of companies we use in the study is 40. This was because we could not obtain complete data on about ten firms for the years included in this study, and we, therefore, dropped these 10 firms from the study.

The principal source of data is an annual document published by the Federal Communications Commission (FCC) titled Statistics of Communications Common Carriers [18]. This lists over 200 Variables, of a financial and operating nature, for the telephone companies reporting to it. In addition to financial and operating firm-level data, it contains macro-economic environmental data which we use for the construction of several of the measures of the independent variables. The other source of data we use is the annual Statistical Abstract of the United States, published by the Bureau of the Census [8].

\subsection{Model and research strategy}

To explain the variations in the adoption levels of new technology we estimate equations of the following general additive form:

$\ln Y_{i j}=\alpha+\sum_{k=1}^{M} \beta_{k} X_{i j} k+e$

where $i, j, M=1,2, \ldots N$ and where $Y_{i j}$ is the dependent variable for the $i$ th firm in the $j$ th time period, $X_{i j} k$ is the $k$ th parameter estimate which is lagged, for the $j$ th period for the $i$ th firm, and $e$ is the error term.

In the above formulation the dependent variable is logged but the independent variables are linear. ${ }^{10}$ The rationale for such a choice is as follows. We wish to estimate changes in the relative proportion of electronic switches to total

10 The dependent variable is also currently bounded half-normally between 0 and 1 since the level of adoption of electronic switches as a proportion of the total switches owned by a firm can range between zero and one. The process of logistic transformation converts the half normal distribution of the adoption data into a log-normal distribution where $\log u$ is assumed to be normal with mean $\mu$ and variance $\sigma$. 
switches adopted by the firms in our sample, and the relationship we seek to evaluate is the impact that the absolute levels of firm and market variables have on the relative proportion of electronic switches. In such situations Gujarati [23] confirms the appropriateness of the above functional form.

We choose two data analysis strategies. A grouped-data strategy study will enable us to identify which variables significantly influence the dependent variable; however, in a study of a changing market environment like that of the US telecommunications industry the overall results so generated may not be wholly insightful because of the structural shifts in the variables. Hence, a grouped-data study, where we identify the key determinants of adoption, needs to be coupled with a comparative analysis of individual cross-sections where we look at the unfolding changes in the technology adoption level associated with changes in both market and firm-level inducements; a dual approach such as this will then help in illuminating issues such as the theoretical significance of the variables in general, and those of causality over time. Such a comparative-statics strategy is particularly useful because while adoption levels are changing over time, the impacts of the different independent variables may also be changing.

We opcrationalize this strategy as follows. For each of four time-periods: 1978, 1981, 1984, and 1987, we obtain cross-sectional data for the 40 telephone operating companies in the sample relating to their proportions of electronic switches on hand. Thereafter, to explain the variations in this dependent variable, independent variables for cach of these firms for prior time-periods: 1973, 1978, 1981, and 1984 are obtained and cross-sectionally matched. That is, data on the dependent variable for 1978 is matched with data on the independent variables for 1973 , and so on. Recollect that we have assumed a lagged relationship between the independent and dependent variables. This cross-sectional data is first grouped, and the grouped database of 160 observations, 40 firms for each of four time-periods, is used to estimate our first regression. In our second regression we introduce time-dummies, so as to control for specific time effects. The years used as a base for comparison, in this linear regression with dummy variables, is the period
1973-1978, since we estimate this regression with dummy variables with an intercept term.

The second set of regressions we estimate as follows. In our grouped-data regression we have controlled for time-effects by introducing dummy variables. Next, we estimate separate regressions for each time-period, where we treat each such time-period as a separate cross-section. Thereby, we augment our analysis by bringing out the changes in the different variables over time and undertake a panel-data study where we look at the same set of 40 firms over four time-periods. As we are taking a behavioral perspective, some of the impacts of the different variables may change as the deregulation proceeds, and our procedures, therefore, enable us to evaluate whether such changes are indeed occurring or not.

Next, in operationalizing our strategy for testing we face the decision of what time points to use for the purpose of analysis. One approach could be to use annual statistics for a given timeperiod of a certain number of years. This can be arbitrary since there are no underlying reasons why the independent variables should change annually or induce a change in the dependent variable in the immediately following year. Rather, based on detailed analysis of the US telecommunications industry context, we use the 5 distinct years, as earlier noted between 1973 and 1987, to be the years with which to carry out our analysis. These 5 years are chosen because they are the years when major milestone events occurred in the history of the industry, and will thus have been the most likely time-periods to impact on firms' strategies.

\subsection{Review of industry events and appropriateness of time-periods selected}

The years chosen for analysis are 1973, 1978, 1981,1984 , and 1987. Dependent variables chosen are those at 1978, 1981, 1984, and 1987; independent variables are those at 1973, 1978, 1981, and 1984. 1973 is chosen because this was the year when technological means of switching between value-added network channels became available. By 1973 industry events led to the recognition that computers and communications were likely to converge. Therefore, firms needed the wherewithal to switch between value-added 
networks. Electronic switches provided firms with the facility to do so, and by 1978 firms would have acted as a result of the forces generated in 1973.

1978 is chosen as a landmark year to commence the study, because this was the year when price competition entered the telecommunications industry, particularly in the long distance area. This price competition was the result of Microwave Communications Inc. (MCI) being allowed to offer switched services as a result of a court reversal of an earlier FCC ruling barring MCI from offering such services. This court ruling virtually opened all major inter-city markets. FCC's response, noted by McAvoy and Robinson [44], was to adapt by lowering other barriers.

1981 marks another critical point in the history of competition in the industry. The FCC issued its final order in Computer Inquiry $I I$ and this decision was regarded as momentous, because it sought to define market structure in terms of the service being offered, rather than the technology being used to do so, as Robinson [54] and Trauth et al. [68] analyze.

1984 was another landmark year in the history of US telecommunications industry with the divestiture of AT \& T of its 22 operating companies. With the reorganization of the telephone industry, and the elimination of many regulatory barriers to competition, the necessary conditions for the development of a competitive environment were created.

We decided to use 1987 as the final year for this study because in the 3 years since the breakup of AT\& T the industry has seen significant developments in long distance competition. The years between 1984 and 1987 also witness major technical developments, in both switches and networks, and, therefore, we feel 1987 will be an appropriate year by which the impact of 1984 events will have been felt.

\subsection{Estimation procedures}

We are dealing with behavioral phenomena to explain variations in the dependent variable. The use of ordinary least squares regression gives undue weight to the idiosyncratic, firm-level factors captured in the residuals of the regression formulation and this reduces the efficacy of the firm-level explanatory variables. Given the wide variations in the adoption levels of new technology noted in the first section, we cannot assume that the distribution of residuals is, therefore, likely to be normal, but, there are likely to be outliers causing fat-tailed disturbances. Such factors tend to cause heteroscedasticity, which we try to control for, in the first instance, by expressing our dependent and independent variables as ratios, a procedure recommended both by $\mathrm{Gu}^{-}$ jarati [23] and Maddala [39]. However, prior studies $[6,71]$ have shown that in the circumstances denoted the use of least absolute value estimators provides improved estimates of the regression coefficients. Therefore, we use the least absolute value (LAV) technique in estimating our equation.

In an OLS equation the least squares estimates are obtained by minimizing the sum of squared residuals. When residuals are squared, large residuals become larger and have a very strong influence on the parameter estimates. Therefore, an alternative procedure is to minimize the sum of absolute crrors, as is done in the LAV technique, rather than the sum of squared errors as in an OLS formulation. This minimizes the effect of large residuals, or outlying observations and provides more efficient estimates of the parameters estimates, as suggested by Maddala [39]. ${ }^{11}$ The estimation of the LAV model reduces to a weightcd lcast squares problem, and also enables us to control for heteroscedasticity since most procedures for correction of heteroscedasticity also reduce to weighted least squares estimation problems.

\subsection{Measures used in testing the model}

\subsubsection{The dependent variable}

LOGSWCH: The adoption level of a firm is measured by the proportion of electronic switches to total switches of the firm at a point in time.

11 Suggestions for the use of the LAV technique go back over two hundred years, and in modern-day economic thought development of ideas related to its use are associated with the name of Edgeworth. However, computational difficulties prevented its use until Charnes et al. [9] showed it was computationally tractable, and the LAV estimator could be obtained as the solution to a linear programming problem. 


\subsubsection{The independent variables}

Variables capturing competitive pressure. Competitive pressure is operationalized using two measures, as follows:

(1) the proportion of business access lines that a firm possesses relative to its total access lines (BUSLNPCT);

(2) the relative urban density of the firm's market (PROPMETRO).

BUSLNPCT: Bolter [7], Langdale [30], Meyer et al. [46], and Wenders [70] have stressed the importance of business customers in generating revenues for telephone companies. Dobell et al. [17] found significant positive long run income elasticities of business incomes with telephone expenditures. These highlight the importance of business customers, and suggest that if a telephone company has a high proportion of such customers it will also have a high degree of exposure to competitive actions.

Within a market faced by local operating companies, business customers are most often the target of other competitors. Therefore, if there is a loss of revenue due to bypass, it is from these business customers. Bypass, as defined by Weisman [69], is a direct connection between a customer's premises and another carrier (service bypass) or self-contained system that avoids services provided by any carrier (facility bypass). Bypass is the most direct threat to operating companies. Where the costs of bypass suppliers are lower than those of operating companies, then bypass is economically justifiable and operating companies will be forced to be more innovative and efficient to compete. Hence, companies with a higher proportion of business customers are more likely to adopt electronic technologies which minimize the risk of bypass by existing customers.

This measure is computed as a ratio of the business lines to total lines possessed by a firm.

PROPMETRO: The second measure relates to the issue of the urban space economy facing each firm in its operating environment. Berg and Pacey [5], Langdale [31] and Meyer et al. [46] suggest that users in large metropolitan areas will be primary targets for competitors' services. The per capita telephone expenditure is greater in metropolitan areas given the greater number of interconnections available. The above studies provide evidence to this effect, and show that the patterns of communication usage exhibit the greatest density in urban areas. Again, the existence of such traffic points to the availability of lucrative markets where bypass can potentially occur. To minimize the risk of bypass, a higher level of adoption of electronic technologies is warranted.

To capture the relative importance of urban density, we calculate a proxy measure, which we term PROPMETRO, as follows. For each state we calculate the proportion of its urban population to total population using the Statistical $A b$ stract of the United States published by the $\mathrm{Bu}$ reau of the Census [8], and arrive at an index for each state. Some telephone companies have operations in one state, while others have multi-state operations. Therefore, for each firm we compute a simple-average of state indices for all the states that it operates in. This denotes the configurations of the urban-space economy for each firm.

Variable-capturing firm effects. Firm effects are operationalized using two measures, as follows:

(3) a measure of performance which is the ratio of cash flow to sales (CF/SALES);

(4) a measure of slack which is the firms share of switches in its area (SWCHSHRE ${ }^{2}$ ).

$C F / S A L E S$ : Performance in any given year is measured by the ratio of cash flow to total sales revenue in that year. Cash flow is computed as the sum of net income available for distribution plus depreciation and amortization expenses. Cash flow to sales is a measure comparable among firms, and also a strong signal available to managers not only about their performance relative to their competitors, but also about the relative wealth generation capacity of the enterprise.

SWCHSHRE ${ }^{2}$ : We measure slack in terms of the proportion of a firm's installed base of switches in its operating area ${ }^{12}$ relative to the total number of all switches in such an operating

12 We measure slack in terms of installed base of switches rather than in financial terms because these are resource rich firms. Therefore, financial slack is likely to be much less powerful than technological slack, which can lead to externalities, in explaining the variations in the technology adoption variable. 
Table 1

Summary of variables used and their measures

\begin{tabular}{|c|c|}
\hline Variable & Measures \\
\hline $\begin{array}{l}\text { New technology } \\
\text { adoption variable }\end{array}$ & $\begin{array}{l}\text { Log of the proportion of } \\
\text { electronic switches to total } \\
\text { switches (LOGSWCH) }\end{array}$ \\
\hline $\begin{array}{l}\text { Competitive pressure } \\
\text { variables }\end{array}$ & $\begin{array}{l}\text { 1. Proportion of a firm's } \\
\text { business access lines to its } \\
\text { total access lines (BUSLNPCT) } \\
\text { 2. Proportion of urban } \\
\text { population in the states that } \\
\text { a firm's operating areas are in } \\
\text { (PROPMETRO) }\end{array}$ \\
\hline Firm effects variables & $\begin{array}{l}\text { 3. Cash flow in any year. } \\
\text { Calculated as net income plus } \\
\text { depreciation and } \\
\text { amortization expenses, divided } \\
\text { by the total sales revenue in } \\
\text { that year (CF/SALES) } \\
\text { 4. This is the square of the } \\
\text { sharc of total switches in the } \\
\text { operating territory a firm } \\
\text { possesses relative to other } \\
\text { firms (SWCHSHRE }{ }^{2} \text { ) }\end{array}$ \\
\hline
\end{tabular}

area. As operating territories are well demarcated for telephone companies in the time-periods we study, the greater the relative installed base, the greater is the network density of a firm. This is because the number of interconnections available rises exponentially with small increases in the installed base, and provides a bigger arena for firms over which to attain the benefits of learning spillovers, as postulated by Sharkey [61].

Second, with a relatively larger network share there can also be economies of scale in implementation of technology through network conver-
Table 3

Expected relationships between the dependent and independent variables

\begin{tabular}{ll}
\hline Independent variables & $\begin{array}{l}\text { Dependent variable: } \\
\text { LOGSWCH }\end{array}$ \\
\hline BUSLNPCT & + \\
PROPMETRO & + \\
CF/SALES & - \\
SWCHSHRE & + \\
\hline
\end{tabular}

sion if switches of a new vintage are adopted. The measure we compute is, however, squared to account for non-linearities that may exist in the learning and conversion economies. The measure is computed, as earlier mentioned, as the proportionate share of total switches that a firm possesses, relative to other competitors in its operating area.

Table 1 summarizes the preceding discussion.

The descriptive statistics for the measures, based on the grouped-data, are given in Table 2 . Finally, the hypothesized relations between the dependent variable and the independent variables are displayed in Table 3.

\section{Results and discussion}

The results of the various regression models run using least absolute value (LAV) estimation procedure are given in Tables 4 and 5 .

The results show that the overall grouped-data model, as given by regression (1), explains $21 \%$ of the variance $\left(R^{2}=0.21\right)$. The $F$-ratio $(10.42)$ is significant (at $P \leq 0.000$ level) indicating there is

Table 2

Means, standard deviations and correlation matrix

\begin{tabular}{|c|c|c|c|c|c|c|c|}
\hline $\begin{array}{l}\text { Serial } \\
\text { number }\end{array}$ & $\begin{array}{l}\text { Variables } \\
\text { (measure) }\end{array}$ & Mean & $\begin{array}{l}\text { Standard } \\
\text { deviation }\end{array}$ & 1 & 2 & 3 & 4 \\
\hline 1 & $\begin{array}{l}\text { New technology } \\
\text { adoption rate } \\
\text { (LOGSWCH) }\end{array}$ & -1.110 & 0.6868 & & & & \\
\hline 2 & $\begin{array}{l}\text { Competitive pressure: } 1 \\
\text { (BUSLNPCT) }\end{array}$ & 0.2616 & 0.0580 & 0.159 & & & \\
\hline 3 & $\begin{array}{l}\text { Competitive pressurc: } 2 \\
\text { (PROPMETRO) }\end{array}$ & 0.7275 & 0.1503 & 0.133 & 0.305 & & \\
\hline 4 & $\begin{array}{l}\text { Firm effect: } 1 \\
\quad(\mathrm{CF} / \text { SALES })\end{array}$ & 0.2846 & 0.0398 & -0.388 & -0.191 & -0.194 & \\
\hline 5 & $\begin{array}{l}\text { Firm effect: } 2 \\
\quad\left(\text { SWCHSHRE }^{2}\right)\end{array}$ & 0.5283 & 0.3502 & 0.376 & 0.330 & 0.096 & -0.550 \\
\hline
\end{tabular}


Table 4

Grouped-data regression results for LOGSWCH

\begin{tabular}{|c|c|c|}
\hline \multirow[b]{2}{*}{$\begin{array}{l}\text { Independent } \\
\text { variables }\end{array}$} & \multicolumn{2}{|c|}{ Parameter estimates } \\
\hline & $\begin{array}{l}\text { Fqn. (1) } \\
\text { without } \\
\text { time-effects }\end{array}$ & $\begin{array}{l}\text { Fqn. (2) } \\
\text { with } \\
\text { time-effects }\end{array}$ \\
\hline Constant & $\begin{array}{c}0.54 \\
(0.95)\end{array}$ & $\begin{array}{l}-1.537 * * * \\
(2.89)\end{array}$ \\
\hline BUSLNPCT & $\begin{array}{r}0.225 \\
(0.24)\end{array}$ & $\begin{array}{r}0.405 \\
(0.50)\end{array}$ \\
\hline PROPMETRO & $\begin{array}{c}0.296 \\
(0.87)\end{array}$ & $\begin{array}{r}0.252 \\
(0.84)\end{array}$ \\
\hline CF/SALES & $\begin{array}{l}-3.926 * * \\
(2.67)\end{array}$ & $\begin{array}{l}-3.461 * * \\
(2.65)\end{array}$ \\
\hline SWCHSHRE $^{2}$ & $\begin{array}{l}0.512 * * * \\
(2.99)\end{array}$ & $\begin{array}{l}0.587 * * * \\
(3.81)\end{array}$ \\
\hline $\begin{array}{l}\text { Time-effect dummy: } \\
1987 / 1984\end{array}$ & - & $\begin{array}{l}1.392 * * * \\
(9.71)\end{array}$ \\
\hline $\begin{array}{l}\text { Time-effect dummy: } \\
1984 / 1981\end{array}$ & - & $\begin{array}{l}0.948 * * * \\
(6.71)\end{array}$ \\
\hline $\begin{array}{l}\text { Time-effect dummy: } \\
1981 / 1978\end{array}$ & - & $\begin{array}{l}0.729 * * * \\
(5.11)\end{array}$ \\
\hline$R^{2}$ & 0.21 & 0.49 \\
\hline$F$ & $10.42 * * *$ & $21.18 * * *$ \\
\hline$N$ & 160 & 160 \\
\hline
\end{tabular}

$t$-statistics are in parentheses; $* * * P<0.005 ; * * P<0.01$; * $P<0.05$.

a good fit of the variables to the data. The results, however, show that of the four independent variables, CF/SALES and SWCHSHRE ${ }^{2}$ are significant explanators of the dependent variable and are in the expected direction, but the effect of BUSLNPCT and PROPMETRO is not found to be significant, although the signs are in the expected direction. This leads, initially, to a broad conclusion that firm-level effects are stronger than market-level effects in explaining the propensity of telecommunications firms to adopt new technology, at least in the period 1973-1987.

Three explanations may be offered why the two competitive pressure variables are not significant explanators of firms' technology adoption patterns in the grouped-data model. First, PROPMETRO captures the urban-space economy of a firm's territory as providing incentives to adopt technology. But a major part of recent urbanization has taken place in suburbia, as opposed to in major city centres, with residential subscribers being a significant part of the market therein. Clearly, it seems that the inducements from the residential sector of the market are not strong in influencing technology adoption patterns of the firms. Second, if business customers are important, as BUSLNPCT measures, there may be different time-periods, for example when the market is opened to competition, when they become more important to the companies.

Finally, these two measures of competitive pressures capture the potential of a firm's environment to generate competition. Much has been written of the competitive potential of an environment in inducing strategic behavior by firms, for example by Baumol et al. [4], Gilbert [21], and Stiglitz [64]. Yet, such inducements caused by the pressures generated by the competitive potential

Table 5

Cross-sectional regression results for LOGSWCH

\begin{tabular}{|c|c|c|c|c|}
\hline \multirow[b]{2}{*}{$\begin{array}{l}\text { Independent } \\
\text { variables }\end{array}$} & \multicolumn{4}{|c|}{ Parameter estimates } \\
\hline & $\begin{array}{l}\text { Eqn. (3) } \\
1978 / 1973\end{array}$ & $\begin{array}{l}\text { Eqn. (4) } \\
1981 / 1978\end{array}$ & $\begin{array}{l}\text { Eqn. (5) } \\
1984 / 1981\end{array}$ & $\begin{array}{l}\text { Eqn. (6) } \\
1987 / 1984\end{array}$ \\
\hline$\overline{\text { Constant }}$ & $\begin{array}{r}0.595 \\
(0.36)\end{array}$ & $\begin{array}{r}0.381 \\
(0.39)\end{array}$ & $\begin{array}{c}-1.85 * * * \\
(3.27)\end{array}$ & $\begin{array}{c}-1.23^{*} \\
(1.67)\end{array}$ \\
\hline RUISI NPCT & $\begin{array}{c}1.232 \\
(0.63)\end{array}$ & $\begin{array}{r}1.922 \\
(1.28)\end{array}$ & $\begin{array}{c}0.930 \\
(0.88)\end{array}$ & $\begin{array}{l}2.080 \\
(1.93)\end{array}$ \\
\hline PROPMETRO & $\begin{array}{c}-2.90 \\
(0.33)\end{array}$ & $\begin{array}{r}-0.274 \\
(0.57)\end{array}$ & $\begin{array}{r}0.352 \\
(1.09)\end{array}$ & $\begin{array}{r}0.489 \\
(1.06)\end{array}$ \\
\hline $\mathrm{CF} / \mathrm{SALES}$ & $\begin{array}{c}-11.401 * * \\
(2.38)\end{array}$ & $\begin{array}{l}-7.872 * * * \\
(2.79)\end{array}$ & $\begin{array}{r}0.339 \\
(0.26)\end{array}$ & $\begin{array}{c}-0.681 \\
(0.42)\end{array}$ \\
\hline SWCHSHRE? & $\begin{array}{l}1.110 * * * \\
(2.61)\end{array}$ & $\begin{array}{c}0.583 * \\
(2.22)\end{array}$ & $\begin{array}{l}0.662 * * * \\
(3.67)\end{array}$ & $\begin{array}{c}-0.086 \\
(0.39)\end{array}$ \\
\hline$R^{2}$ & 0.45 & 0.55 & 0.45 & 0.21 \\
\hline$F$ & $7.20 * * *$ & $10.80 * * *$ & $7.27 * * *$ & $2.31 *$ \\
\hline$N$ & 40 & 40 & 40 & 40 \\
\hline
\end{tabular}

$t$-statistics are in parentheses; ${ }^{*} * P<0.005 ;{ }^{*} * P<0.01 ;{ }^{*} P<0.05$. 
of the environment may have a clear time trend. It is, therefore, appropriate to review the impact of each of these variables in a series of cross-sectional regressions undertaken over each timeperiod.

Prior to reporting the results of the cross-sectional regression, we report results of eqn. (2) where we run the grouped-data regression, but with the addition of dummies to control for time-effects. The equation has a $R^{2}$ of 0.49 , with a $F$ value of 21.18 . Both variables that were significant in eqn. (1), viz. CF/SALES and SWCHSHRE $^{2}$ capturing firm-level effects, are again significant. Therefore, firm-level effects do seem to matter in inducing firms to adopt new technology. The three time dummies are also all significant. When we compare the $t$ statistics for each versus the base-line case, which is the set of observations for $1978 / 1973,{ }^{13}$ the most significant change has been in $1987 / 1984$ vis-à-vis 1978/1973.

The empirical results provided in Table 5 provide strong support for the behavioral hypotheses that past performance will be negatively related to adoption levels and positively related to slack availability. The strong relation between poor performance and adoption levels is consistent with the failure-inducement hypothesis of Antonelli [2] and Mansfield [42]. Antonelli [2] discovered that R\&D expenditures of Italian firms increased during periods of poor performance, consistent with the failure-inducement hypothesis derived from the behavioral theory of the firm. Our results also lend strong support to the positive relation between availability of technical slack and adoption levels. This is consistent both with the behavioral theory of the firm [12,43], and with Lelbenstein's insight [32-34] that slack induces managers to expend efforts at gaining control of such slack, in order to deploy it in an attempt to promote one's own career, but also in the process promoting the welfare of the firm.

13 Recall that in our regression models we have a lag structure where variations in the dependent variable are explained by independent variables from a previous timeperiod. Thus the adoption level in 1978 is thought to be explained by variations in the independent variables for 1973. Each of these cross-sectional runs is referred to by the years the dependent and independent variables in each one are concerned with, e.g. 1987/1984, 1984/1981, $1981 / 1978$ and $1978 / 1973$.
If the relative size of the $t$ statistics is used as a guide to compare the effects between different time-periods, then it is also seen that there has been a major increase in adoption in 1987/1984 vs. $1984 / 1981$. This is the phase when the deregulatory moves took place. But the difference in the $t$ statistics between $1984 / 1981$ and 1981 $/ 1978$ is not so large. The results of this equation tell us that firm-effects and effects of time in generally help us explain adoption levels of new technology. However, a more revealing set of analyses will be to look at the influence of the variables in the separate cross-sectional regressions, given in Table 5.

Equations (3)-(6) are the cross-sectional equations for the periods 1978/1973, 1981/1978, $1984 / 1981$ and $1987 / 1984$, respectively. The respective $R^{2}$ are $0.45,0.55,0.45$ and 0.21 . These are all significant, and again our model seems to explain the underlying variations in the levels of new technology adoptions by telecommunications firms reasonably well. However, what is of interest is the dynamics of how the different variables impact at different time-periods.

In eqns. (3) and (4), for the periods 1978/1973 and 1981/1978, the firm-level effects are very significant. They are of the right sign, as we have posited. However, the competitive pressure variables are not yet significant. It seems that during these two time-periods, when measures to makc the industry competitive are only starting, firms with a strong performance are not yet induced to be aggressive in technology adoption; relatively strong performance seems to breed complacency, and, therefore, we witness the negative and significant coefficients for the CF/SALES variable. Conversely, the ability to exploit existing systems-scale economies in a local monopoly situation, as these firms face and as captured by the SWCHSHRE $^{2}$ variable, does induce firms to be aggressive adopters. The existence of scale economics can lead to network externalities and the ability of firms to exploit market power; these then induce intra-firm rent-seeking behavior which is reflected in new technology adoption decisions.

Equations (5) and (6) capture the effects for the periods $1984 / 1981$ and $1987 / 1984$. In eqn. (5) the SWCHSHRE $^{2}$ variable is significant, suggesting that during the transition period, the dynamics of which this cross-section captures, 
network externalities, and the ability to lock-in existing customers to the installed base, are important in inducing firms to adopt new technology. However, the non-significance of the CF/SALES variable in these two equations has some very interesting implications. 1978 marked the beginning of serious moves to introduce com. petition into the US telecommunications industry. The possible import of this structural change does not seem to have been lost, even on those firms which are in a relatively more comfortable resource position compared to others; indeed, there seems to be a realization that existing cashflows can be quite easily attacked by others. If at the moment the better performing firms are not induced by their wealth-generating ability to be aggressive in new technology adoption, they certainly are no longer behind either, as they seemed to be, according to the past negative signs on the CF/SALES variable.

The fact that competitive pressures matter very much in the latter time-periods of our study is brought home by eqn. (6). There we note that the firm-level variables are not significant in inducing new technology adoption. But what is significant, and of the right sign, is the BUSLNPCT variable. Business customers account for a significant chunk of these firms' income and profits; they are also the customers most subject to bypass. Therefore, those firms with the greater proportion of business customers would be hurt the most if these customers were to be lost. Hence, a way to avoid own customer predation through bypass activities by competitors, or by bypass activities of the customers themselves, is to have state of the art technology, and this seems to be the inducement for electronic switch adoption in the 1987/1984 period.

\section{Conclusion}

This study began with the observation that new technology adoption levels were not uniform across firms in the telecommunications industry. However, this phenomenon is not unique to this industry alone, and the findings may have broader implications for other industries too. Technical progress is critical for enhancing productivity and welfare. The benefits of such progress can only be felt if firms adopt new technology, and can utilize the benefits to offer new products and cut costs. Therefore, understanding firm-level factors as to what influences such adoption behavior is crucial for both business and public policy. Our study, which looked at the determinants of technology adoption in a major infrastructure industry while a unique natural experiment in industrial organization was taking place therein, thus sheds some light on what are the key factors that seem to influence firms as the industries that they are a part of evolve.

In our attempts to explain the non-uniformity in the levels of adoption of new technology in the telecommunications industry we have employed a distinctly behavioral perspective, rather than emphasizing the cost-benefit tradeoffs of a new technology under a purely rational-choice analysis. Firms are not necessarily rational in their behavior, but as a collection of human agents, react differently not only to the differential incentives and pressures provided by the market, but also those provided within the firm hierarchy. Thus, our findings in this study lend support to behavioral explanations for managerial actions of an exceedingly important nature. Our results also show that different forces are at work at different points during the evolution of technology and the regulatory environment within an industry.

The behavioral perspective sheds two crucial insights into the propensity for innovative behavior on the part of firms. First is the idea that the existence of competition is an important motive for engaging in innovative activity. But particularly important is the competition which manifests itself in the form of specific pressures in the micro-market of a firm. These micro-market pressures have significant behavioral consequences, leading to changes in overall firm behavior. When pressures are close to home, and actual rather than potential,or future cash flows are likely to disappear, incentives to be modern manifest themselves more significantly. Thus, we find that competitive pressure, as captured by more micro-measures is a better predictor of adoption decisions than the broad competitiveness of the environment, which is generally captured by macro-measures such as concentration or other market structure constructs.

The second powerful idea within the behavioral perspective is that past performance and slack availability are important motivators for en- 
gaging in innovative activity. These insights are of sufficient generality that they apply not only to new technology adoption, but could easily be extended to explain differences in the propensity of firms to engage in or invest in innovative or $\mathrm{R} \& \mathrm{D}$ activity.

Finally, this study may be extended along several dimensions. First, it will be interesting to evaluate if some firms are habitually more innovative than others; that is, do some firms have a systematically greater propensity to adopt new innovations independent of performance or slack. Second, data can be obtained on an annual basis to understand the dynamic nature of the process of adoption, both at the industry level and at the individual firm level. Third, one can investigate the effects of the experience with initial adoption on subsequent adoption levels within the firm; that is, what are the effects of learning on future strategic behavior. Finally, one can investigate the nature of performance differences between the early adopters and late adopters of a new technology.

\section{References}

[1] 7. Acs and D. B. Audretsch (Editors), Innovation and Technical Change: An International Comparison (The University of Michigan Press, Ann Arbor, MI, 1991).

[2] C. Antonelli, A Failure Inducement Model of Research and Development, Journal of Economic Behavior and Organization 12 (1989) 159-180.

[3] K.J. Arrow, Economic Welfare and the Allocation of Resources for Inventive Activity, in: R.R. Nelson (Editor), The Rate and Direction of Inventive Activity (Princeton University Press, Princeton, NJ, 1962).

[4] W.J. Baumol, J.C. Panzar and R.D. Willig, Contestable Markets and the Theory of Industrial Structure (Harcourt, Brace, Jovanovich, Inc., New York, 1982).

[5] S. Berg and P. Pacey, Impact of Deregulation on Pointto-Point Demand in the U.S.A., Telecommunications Policy (December 1982) 309-314.

[6] R. Blattberg and T. Sargent, Regression with Non-Gaussian Stable Disturbanccs: Some Sampling Results, Econometrica 39 (1971) 501-510.

[7] W.G. Bolter (Editor), Telecommunications Policy for the 1980s: The Transition to Competition. Published for the Washington Program, The Annenberg Schools of Communication (Prentice-Hall, Englewood Cliffs, NJ, 1984).

[8] Bureau of the Census, Statistical Abstract of the United States (U.S. Department of Commerce, Washington, D.C., Annual).

[9] A. Charnes, W.W. Cooper and R.O. Ferguson, Optimal Estimation of Compensation by Linear Programming, Management Science 1 (1955) 138-151.
[10] K. Clark, Investment in New Technology and Competitive Advantage, in: D.J. Teece (Editor), The Competitive Challenge (Harper \& Row, New York, 1987).

[11] R.W. Crandall and K. Flamm, Overview, in: Robert W. Crandall and Kenneth Flamm (Editors), Changing the Rules: Technological Change, International Competition and Regulation in Communications (The Brookings Institution, Washington, DC, 1989).

[12] R.M. Cyert and J.G. March, A Behavioral Theory of the Firm (Prentice-Hall, Englewood Cliffs, NJ, 1963).

[13] P. Dasgupta and J.E. Stiglitz, Industrial Structure and the Nature of Innovative Activity, Economic Journal 90 (1980) 266-293.

[14] P. Dasgupta, The Theory of Technological Competition, in: J.E. Stiglitz and G.F. Mathewson (Editors), New Developments in the Analysis of Market Structure (The MIT Press, Cambridge, MA, 1986) pp. 519-547.

[15] S. Davies, The Diffusion of Process Innovations (Cambridge University Press, Cambridge, 1979).

[16] R. Dixon, Hybrid Corn Revisited, Econometrica 48 (1980) 1451-1461.

[17] R. Dobell, L.D. Taylor, L. Waverman, T.H. Liu and M.D.G. Copeland, Telephone Communication in Canada: Demand, Production and Investment Decisions, Bell Journal of Economics and Management Science 5 (1972) 175-219.

[18] Federal Communications Commissions, Statistics of Communications Common Carriers (Washington, D.C., annual).

[19] K. Flamm, Technological Advance and Costs: Computers versus Communications, in: Robert W. Crandall and Kenneth Flamm (Editors), Changing the Rules: Technological Change, International Competition and Regulation in Communications (The Brookings Institution, Washington, DC, 1989).

[20] D. Fudenberg and J. Tirole, Preemption and Rent Equalization in the Adoption of New Technology, Review of Economic Studies 52 (1985) 383-401.

[21] R.J. Gilbert, The Role of Potential Competition in Industrial Organization, Journal of Economic Perspectives 3.3 (1989) 107-128.

[22] Z. Griliches, Hybrid Corn: An Exploration in the Economics of Technological Change, Econometrica 25(4) (1957) 501-522

[23] D. Gujarati, Basic Econometrica, 2nd edn (McGraw-Hill, New York, 1986).

[24] T.H. Hannan and J.M. McDowell, Market Concentration and the Diffusion of New Technology in the Banking Industry, Review of Economics and Statistics 66 (1984) $686-691$.

[25] T.H. Hannan and J.M. McDowell, The Determinants of Technology Adoption: The Case of the Banking Firms, Rand Journal of Economics 15 (1984) 328-335.

[26] M. Kamien and N. Schwartz, Market Structure Elasticity of Demand, and Incentive to Invent, Journal of Law and Economics 13 (1970) 241-252.

[27] M. Kamien and N. Schwartz, Potential Rivalry, Monopoly Profits and the Pace of Inventive Activity, Review of Economic Studies 45 (1978) 547-557.

[28] M. Kamien and N. Schwartz, Market Structure and Innovation (Cambridge University Press, Cambridge, 1982). 
[29] S.J. Lane, The Determinants of Investment in New Technology, American Economic Review 81.2 (May 1991) 262-265.

[30] J. Langdale, Competition in Telecommunications, Telecommunications Policy (December 1982) 283-299.

[31] J. Langdale, Competition in the US Long-Distance Telecommunications Industry, Regional Studies 17(6) (1983) 393-409.

[32] H. Leibenstein, Organizational and Frictional Equilibria, X-Efficiency and the Role of Innovation, Quarterly Journal of Economics 83 (1969) 600-623.

[33] H. Leibenstein, Beyond Economic Man: A New Foundation for Microeconomics (Harvard University Press, Cambridge, MA, 1976).

[34] H. Leibenstein, A Branch of Economics is Missing: Micro-Micro Theory, Joumal of Economic Literature 17 (1979) $477-502$.

[35] S.G. Levin, S.L. Levin and J.B. Meisel, A Dynamic Analysis of the Adoption of a New Technology: The Case of Optical Scanners, Review of Economics and Statistics 69 (1987) 12-17.

[36] D. Levinthal and J.G. March, A Model of Adaptive Organizational Search, Journal of Economic Behavior and Organization 2 (1981) 307-333.

[37] D. Levy, The Speed of the Invisible Hand, International Journal of Industrial Organization 5 (1987) 79-92.

[38] G. Loury, Market Structure and Innovation, Quarterly Journal of Economics 93 (1979) 395-410.

[39] G.S. Maddala, Economics (McGraw-Hill, New York, 1977).

[40] E. Mansfield, Technical Change and the Rate of Imitation, Econometrica 2 (1961) 741-766.

[41] E. Mansfield, The Speed of Response of Firms to New Techniques, Quarterly Journal of Economics 77 (1963) 290-311.

[42] E. Mansfield, The Economics of Technological Change (Norton and Co., New York, 1968).

[43] J.G. March and H.A. Simon, Organizations (Wiley, New York, 1958).

[44] P.W. McAvoy and K. Robinson, Winning by Losing: The AT\&T Settlement and its Effect on Regulation, Yale Journal of Regulation 1.1 (1983) 1-42.

[45] J.S. Metcalfe, Diffusion of Innovation in the Lancashire Textile Industry, Manchester School of Economic and Social Studies 38 (1970) 145-162.

[46] J.R. Meyer, R.W. Wilson, M.A. Baughcum, E. Burton and $\mathrm{L}$. Caouette, The Economics of Competition in the Telecommunications Industry (Oelgeschlager, Gunn and Hain, Publishers, Inc., Cambridge, MA, 1980).

[47] D. Mookherjee and D. Ray, On the Competitive Pressures Created by the Diffusion of Innovations, Journal of Economic Theory, 54 (1991) 124-147.

[48] E. Penrose, The Theory of the Growth of the Firm (Wiley, New York, NY, 1959).

[49] H.C. Quirmbach, The Diffusion of New Technology and the Market for an Innovation, Rand Joumal of Economics 17 (1986) 3347.

[50] J.F. Reinganum, On the Diffusion of New Technology: A Game Theoretic Approach, Review of Economic Studies 48 (1981) 395-405.

[51] J.F. Reinganum, Market Structure and the Diffusion of New Technology, Bell Journal of Economics 12 (1981) $618-624$.
[52] J.F. Reinganum, Dynamic Games of Innovation, Journal of Economic Theory 25 (1981) 21-41.

[53] J.F. Reinganum, The Timing of Innovation: Research Development, and Diffusion, in: R. Schmalensee and R. Willig, Handbook of Industrial Organization, Volume 1 (Elsevier Science Publishers, New York, 1989).

[54] G.O. Robinson. The Titanic Remembered: AT\&T and the Changing World of Telecommunications. Book Review of Telecommunications in Turmoil: Technology and Public Policy by C. Faulhaber, published by Ballinger Publishers, Cambridge, MA. Yale Journal of Regulation 5.2 (1988) 517-545.

[55] T. Robinson, Depreciation Reserve Assessment, in; Albert L. Danielson and David R. Kamerschen (Editors), Telecommunications in the Post Divestiture Era (D.C. Heath, Lexington, MA, 1986).

[56] E. Rogers, Diffusion of Innovations, 3rd edn (Free Press, New York, 1983).

[57] D.I. Rosenbaum, The Impact of Market Structure on Technological Adoption in the Portland Cement Industry, Quarterly Review of Economics and Business 29(3) (1989) 102-110.

[58] F.M. Scherer, Research and Development Resource Allocation Under Rivalry, Quarterly Joumal of Economics 81 (1967) 359-394.

[59] J. Schmookler, Invention and Economic Growth (Harvard University Press, Cambridge, MA, 1966).

[60] J.A. Schumpeter, Capitalism, Socialism and Democracy (Harper \& Row, New York, 1975).

[61] W.W. Sharkey, The Theory of Natural Monopoly (Cambridge University Press, New York, 1982).

[62] R.E. Skoog, The Design and Cost Characteristics of Telecommunications Networks (AT\&T Bell Laboratories, Murray Hill, NJ, 1980).

[63] R. Solow, Technical Change and the Aggregate Production Functions, Review of Economics and Statistics (August 1957).

[64] J.E. Stiglitz, Introduction, in: Joseph E. Stiglitz and G. Frank Mathewson (Editors), New Developments in the Analysis of Market structure (The MIT Press, Cambridge, MA, 1986).

[65] P. Stoneman, Technological Diffusion and the Computer Revolution, The U.K. Experience (Cambridge University Press, Cambridge, 1976).

[66] P. Stoneman, The Economic Analysis of Technological Change (Oxford University Press, Oxford, 1983).

[67] C.G. Thirtle and V.W. Ruttan, The Role of Demand and Supply in the Generation and Diffusion of Technical Change (Harwood Academic Publishers, New York, 1987).

[68] E. Trauth, D. Trauth, and J. Huffman, Impact of Deregulation on Marketplace Diversity in the U.S.A.), Telecommunications Policy (June 1983) 11-20.

[69] D.L. Weisman, Default Capacity Tariffs: Smoothing the Transitional Regulatory Asymmetries in Telecommunications Markets, Yale Journal of Regulation 5 (1988) 149178.

[70] J.T. Wenders, The Economic Theory of Regulation and the U.S. Telecommunications Industry, Telecommunications Policy (March 1988) 16-26.

[71] R. Zeckhauser and $\mathbf{M}$. Thompson, Linear Regression with Non-Normal Error Terms, Review of Economics and Statistics 52 (1970) $280-286$. 